\title{
Financial burden associated with the residency match in neurological surgery
}

\author{
Nitin Agarwal, MD, ${ }^{1}$ Phillip A. Choi, BS, ${ }^{1}$ David O. Okonkwo, MD, PhD, ${ }^{1}$ Daniel L. Barrow, MD, ${ }^{2}$ and \\ Robert M. Friedlander, MD, MA ${ }^{1}$
}

\begin{abstract}
1Department of Neurological Surgery, University of Pittsburgh Medical Center, Pittsburgh, Pennsylvania; and 2Department of Neurosurgery, Emory University School of Medicine, Atlanta, Georgia
\end{abstract}

\begin{abstract}
OBJECTIVE Application for a residency position in neurosurgery is a highly competitive process. Visiting subinternships and interviews are integral parts of the application process that provide applicants and programs with important information, often influencing rank list decisions. However, the process is an expensive one that places significant financial burden on applicants. In this study, the authors aimed to quantify expenses incurred by 1st-year neurosurgery residents who matched into a neurosurgery residency program in 2014 and uncover potential trends in expenses.
\end{abstract}

METHODS A 10-question survey was distributed in partnership with the Society of Neurological Surgeons to all 1styear neurosurgery residents in the United States. The survey asked respondents about the number of subinternships, interviews, and second looks (after the interview) attended and the resultant costs, the type of program match, preferences for subinternship interviews, and suggestions for changes they would like to see in the application process. In addition to compiling overall results, also examined were the data for differences in cost when stratifying for region of the medical school or whether the respondent had contact with the program they matched to prior to the interview process (matched to home or subinternship program).

RESULTS The survey had a $64.4 \%$ response rate. The mean total expenses for all components of the application process were US $\$ 10,255$, with interview costs comprising the majority of the expenses $(69.0 \%)$. No difference in number of subinternships, interviews, or second looks attended, or their individual and total costs, was seen for applicants from different regions of the United States. Respondents who matched to their home or subinternship program attended fewer interviews than respondents who had no prior contact with their matched program (13.5 vs 16.4, respectively, $p=$ 0.0023 ) but incurred the same overall costs (mean $\$ 9774$ vs $\$ 10,566 ; p=0.58$ ).

CONCLUSIONS Securing a residency position in neurosurgery is a costly process for applicants. No differences are seen when stratifying by region of medical school attended or contact with a program prior to interviewing. Interview costs comprise the majority of expenses for applicants, and changes to the application process are needed to control costs incurred by applicants.

http://thejns.org/doi/abs/10.3171/2015.12.JNS15488

KEY WORDS neurological surgery; residency; match; interview; cost; graduate medical education; National Resident Matching Program; survey; questionnaire

$\mathrm{O}$ BTAINING a position in a neurological surgery residency training program is a competitive endeavor, with costs borne disproportionately by the applicants. Neurosurgery residency programs universally participate in the National Resident Matching Program (NRMP). In 2009, 295 applicants applied for 191 residency positions in neurosurgery, representing an applicant- to-position ratio of $1.5{ }^{6}$ Successfully matched applicants had a mean United States Medical Licensing Examination (USMLE) Step 1 score of 239, with an average of 7.8 abstracts, presentations, and publications. In 2014, the ratio of applicants to residency positions was stable at 1.5; however, the mean USMLE Step 1 score increased to 244, and the mean number of abstracts, presentations, and pub-

ABBREVIATIONS IQR = interquartile range; NRMP = National Resident Matching Program; SD = standard deviation; SNS = Society of Neurological Surgeons; USMLE = United States Medical Licensing Examination.

SUBMITTED March 2, 2015. ACCEPTED December 4, 2015.

INCLUDE WHEN CITING Published online April 8, 2016; DOI: 10.3171/2015.12.JNS15488. 
lications increased to 11.7. ${ }^{7}$ Unfortunately, in addition to being competitive, applying for a neurosurgical residency position is also an expensive process.

The high costs of applying to a neurosurgical residency are largely due to the informal requirement of subinternships as a visiting student and the large number of interviews typically attended. Subinternships and in-person interviews at each program are important components of the neurosurgery match. Subinternships give students an opportunity to learn more about the many facets of programs they may potentially be interested in. Students gain insight into alternative approaches to pathologies that may differ from those of their home institution as well as learn more about the culture of the program, the residents and faculty, and the city. Subinternships also act as an indicator to programs of a student's serious exploration of and commitment to the field, and offer an opportunity to evaluate students with much more depth than can usually be done in 1 or 2 days of interviewing. In-person interviews are important to both students and programs because they give parties an opportunity to get to know the places and people they might work with for the next 7 years, which can have major influence on a student's career.

However, all of the benefits of subinternships and inperson interviewing come at a significant cost to applicants. For subinternships, applicants must travel to a program and bear the costs of housing and transportation for a month. Many students do multiple subinternships. Due to the relatively small number of neurosurgery residency programs (102 in the 2014 match), small number of positions at each program (206 positions initially planned for the 2014 match), and overall competitiveness of the applicant pool, applicants typically apply to a wide geographic range of programs. ${ }^{8}$ The costs of travel and lodging for interviews can be significant, especially when multiple trips are made to the same region of the country since programs do not coordinate their interview schedules. These costs are particularly relevant to neurosurgery and a handful of other competitive surgical specialties with limited residency programs, such as orthopedic surgery, otolaryngology, and plastic surgery.

The goal of this study was to determine the costs to applicants of applying for a neurosurgical residency position and gain direct feedback regarding practical potential steps that could be taken to reduce costs. We sought to examine how various applicant-based factors may influence the financial burden of applying for a neurosurgical residency.

\section{Methods}

In partnership with the Society of Neurological Surgeons (SNS), a 10-item survey was sent in early November 2014 to the chairmen and program coordinators at every neurosurgical residency program in the United States to pass on to their 1st-year residents who matched in the 2014 NRMP. The survey included both fill-in-the-blank and multiple-choice questions regarding the number of subinternships completed, interviews attended, and second looks attended after the interview, the cost of traveling for each of these events, whether the applicant had exposure to the residency program prior to interviewing, and preferences for interviewing during a subinternship (Table 1). A free-response section at the end of the survey asked for comments or suggestions regarding interviewing.

Normality of variables was assessed using the Kolmogorov-Smirnov test. Normally distributed continuous variables are presented as means and standard deviations (SDs). Medical schools were ranked and categorized into quartiles using the U.S. News \& World Report's Best Medical Schools: Research Rankings. ${ }^{12}$ Tests of statistical significance include 2-tailed t-test dichotomous comparisons and analysis of variance for greater than 2 groups. Non-normal distribution of continuous variables is presented as medians and interquartile ranges (IQRs) (25th to 75th percentile), and tests of statistical significance include

TABLE 1. Summary of survey responses received from 130 current postgraduate 1st-year neurosurgery residents

\begin{tabular}{|c|c|}
\hline Item & Value \\
\hline $\begin{array}{l}\text { Attended medical school with residency } \\
\text { program, } \%\end{array}$ & 75.4 \\
\hline No. of subinternships completed, median (IQR) & $3(2-3)$ \\
\hline No. of interviews attended, mean \pm SD & $15.3 \pm 5.4$ \\
\hline No. of second looks attended, median (IQR) & $1(0-2)$ \\
\hline \multicolumn{2}{|l|}{ Cost } \\
\hline \multicolumn{2}{|l|}{ Subinternships } \\
\hline Mean \pm SD & $\$ 2840 \pm \$ 2360$ \\
\hline Median & $\$ 2100$ \\
\hline IQR & $\$ 1500-3000$ \\
\hline$\%$ of total expense & 28.3 \\
\hline \multicolumn{2}{|l|}{ Interviews } \\
\hline Mean \pm SD & $\$ 7180 \pm \$ 3880$ \\
\hline Median & $\$ 7000$ \\
\hline IQR & $\$ 4500-10,000$ \\
\hline$\%$ of total expense & 69.0 \\
\hline \multicolumn{2}{|l|}{ Second looks } \\
\hline Mean \pm SD & $\$ 293 \pm \$ 450$ \\
\hline Median & $\$ 50$ \\
\hline IQR & $\$ 0-500$ \\
\hline$\%$ of total expense & 2.8 \\
\hline \multicolumn{2}{|l|}{ Total } \\
\hline Mean \pm SD & $\$ 10,300 \pm \$ 5170$ \\
\hline Median & $\$ 10,000$ \\
\hline IQR & $\$ 6500-13,000$ \\
\hline \multicolumn{2}{|l|}{ Matched into, \% } \\
\hline Home & 17.7 \\
\hline Subinternship & 21.5 \\
\hline Second look & 13.9 \\
\hline Other program & 36.9 \\
\hline No response & 10.0 \\
\hline \multicolumn{2}{|l|}{ Preference for subinternship interviews, $\%$} \\
\hline During subinternship & 33.1 \\
\hline During formal interview process & 50.0 \\
\hline No response & 16.9 \\
\hline
\end{tabular}


the Wilcoxon rank-sum test for dichotomous comparisons and the Kruskal-Wallis test for greater than 2 groups. Post hoc paired comparisons were adjusted for using the conservative Bonferroni correction. For categorical variables, frequencies and percentages are reported, and statistical significance was calculated using the Fisher exact test or chi-square test. Correlation between 2 variables was measured using Pearson correlation coefficient. Results were considered statistically significant for $p$ values less than 0.05 . Statistical analyses were conducting using Stata 13 (StataCorp), and maps of respondent location were generated using R 3.1.1 and the ggplot2 package.

\section{Results}

Responses were received from 130 of 202 current postgraduate 1st-year neurosurgery residents, corresponding to a $64.4 \%$ response rate. The distribution of the respondents' medical schools and residency programs was graphically depicted (Supplemental Figs. 1 and 2, respectively). All respondents completed the first 8 questions of the survey, which included the name of the medical school, name of the residency program, and the number and cost of subinternships, interviews, and second looks attended. A total of $90.0 \%$ of respondents (117 residents) answered the ninth question (matched into home, subinternship, second look, or other program), and $83.1 \%$ respondents (108 residents) answered the tenth question (subinternship interview preference: during the subinternship or during the formal interview process). Eight respondents added suggestions or comments regarding the interviewing process.

Table 1 summarizes the results for the entire group of respondents. Respondents completed a median of 3 sub- internships (IQR 2-3), attended a mean of $15.3 \pm 5.4$ interviews, and attended a median of 1 second look (IQR $0-2)$. Almost half of the respondents $(46.2 \%)$ did not attend any second looks. The corresponding mean costs for subinternships, interviews, and second looks were US \$2840 (median \$2100, IQR \$1500-\$3000); \$7180 (median $\$ 7000$, IQR \$4500-\$10,000); and \$293 (median \$50, IQR $\$ 0-\$ 500)$, respectively. The mean total cost of the entire application process was $\$ 10,300$ (median $\$ 10,000$; IQR \$6500-\$13,000), with interview expenses comprising the largest proportion (69.0\%), followed in descending cost by subinternships $(28.3 \%)$ and then second looks $(2.8 \%)$. Some $17.7 \%$ of respondents matched their home program, $21.5 \%$ matched a subinternship site, $13.9 \%$ matched a program where they attended a second look, and 36.9\% matched a program they did not have contact with other than the interview (Fig. 1). Half of respondents stated they would prefer to have interviews for subinternship sites through the formal interview process, while $33.1 \%$ stated they would prefer to complete these interviews during the subinternship (Fig. 2). A moderate correlation was found between the number of interviews attended and the cost of interviews (Pearson correlation coefficient $=0.61$ ).

Stratifying survey results by whether applicants had contact with the program they matched prior to the interview process (home or subinternship) versus those who matched at programs they did not have contact with prior to the interview process (attended second look or only contact was interview) reveals almost no difference between the 2 groups (Supplemental Table 1). Respondents who had no prior contact with the program to which they matched attended more interviews than those who matched their home or subinternship program (16.4 vs 13.5 interviews

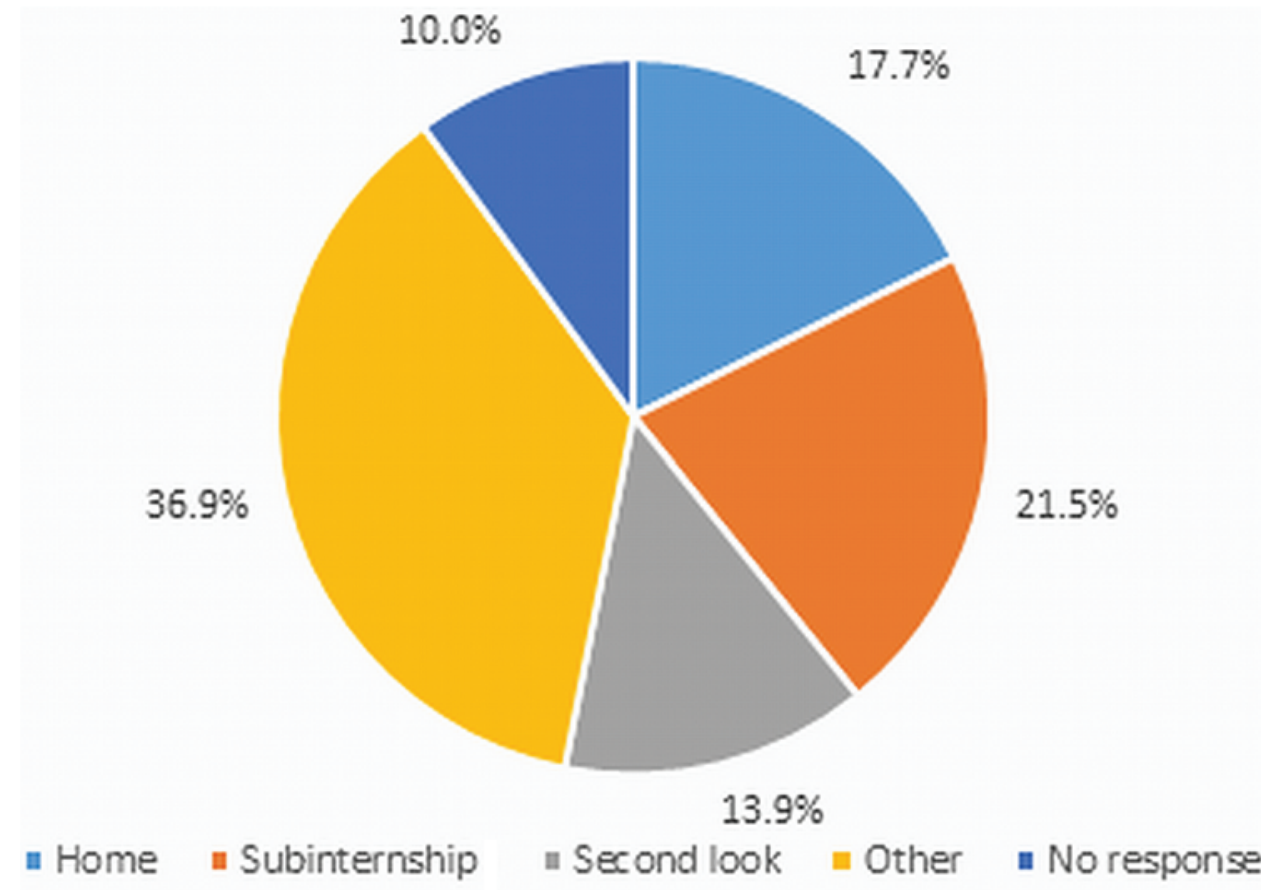

FIG. 1. Pie chart showing the program match type for 117 of 130 respondents who answered this question. Twenty-three respondents matched into their home program, 28 into subinternships, 18 into second looks, and 48 into other program. Thirteen residents did not answer this question. Figure is available in color online only. 


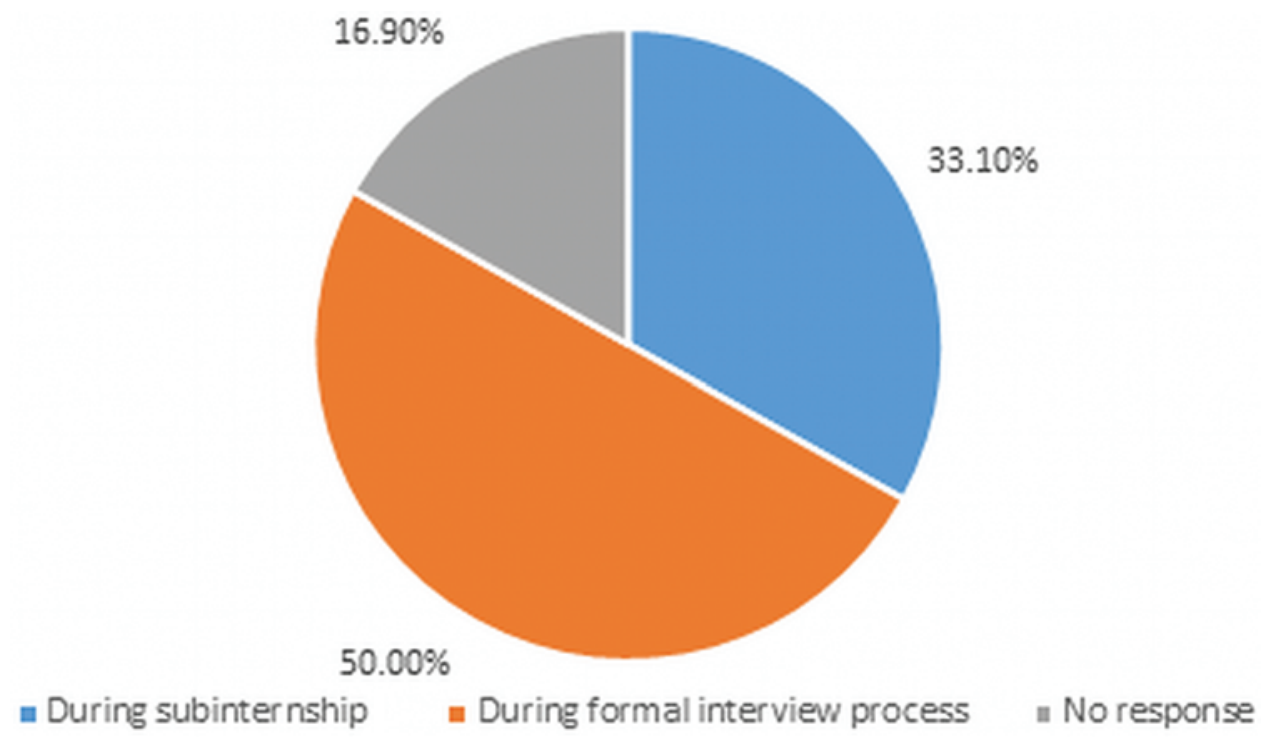

FIG. 2. Pie chart showing applicant preferences for the subinternship interviews. Of the 130 respondents, 108 answered this question; 43 respondents preferred interviewing during their subinternship, and 65 preferred interviewing during the formal interview process. Twenty-two residents did not answer this question. Figure is available in color online only.

attended, respectively, $\mathrm{p}=0.0023$ ). However, there was no difference in interview-related costs for the 2 groups, nor was there any difference in total expenses. No other statistically significant difference was found in the survey items of interest.

Results of the survey were stratified by the region of the respondents' medical school (Supplemental Table 2). Medical school regions were based on divisions set by the SNS (https://www.societyns.org/match_information. html). ${ }^{12}$ No differences were observed for responses to any survey question across the 6 regions of the United States.

Analyses of survey results after ranking and categorizing medical schools by quartiles were conducted (Supplemental Table 3). A statistically significant difference was detected in the number of second looks attended. Multiple comparisons of number of second looks attended revealed a significant difference between the 1st and 4th quartiles (mean 1.55 versus 0.63 second looks attended, respectively, $\mathrm{p}=0.0162$ ). No significant differences between quartiles were detected for number of subinternships or interviews attended. Likewise, no differences were seen in subinternship, interview, second look, or total expenses. The same pattern is seen when stratifying school ranking by top 10 versus all others (Supplemental Table 4).

Figure 3 illustrates the number of second looks attended stratified by type of program match. As previously noted, $46.2 \%$ of respondents did not attend a second look. There was significant association between type of program match and number of second looks attended ( $\mathrm{p}$ $=0.0001)$. Respondents who matched into a second look

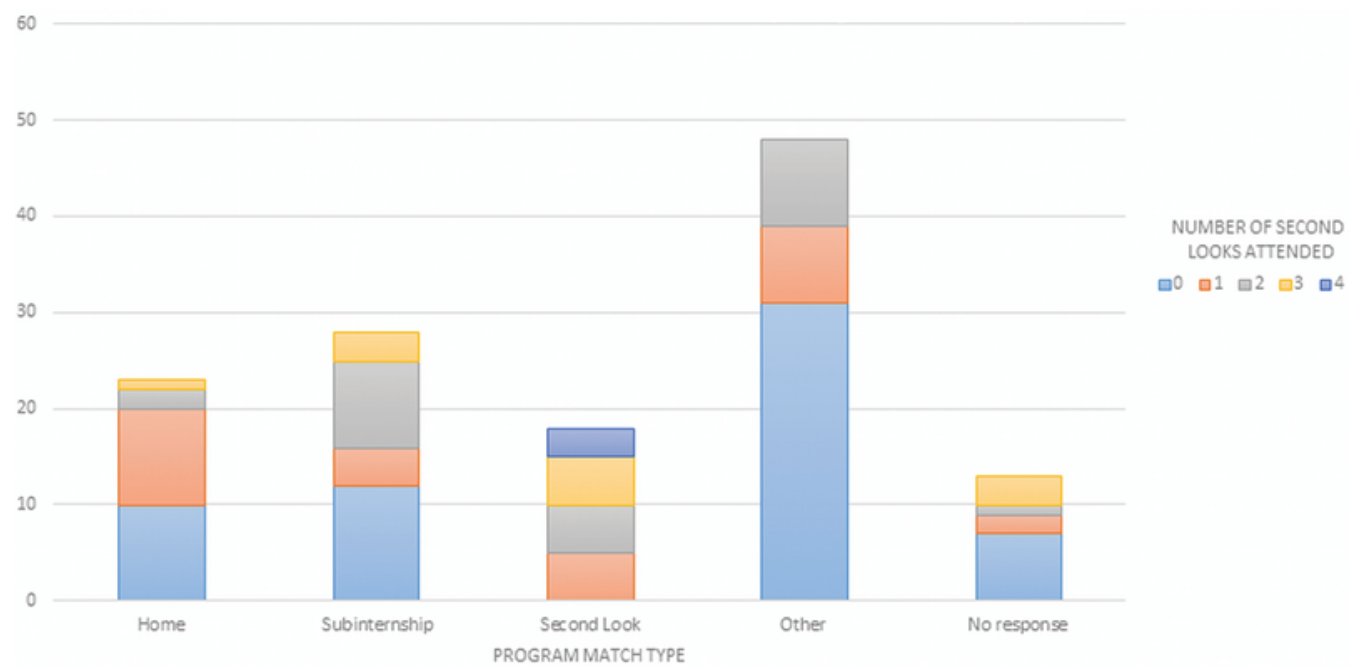

FIG. 3. Bar graph showing the number of second looks attended stratified by program match type. Of the 130 respondents, 23 $(17.7 \%)$ matched into a home program, $28(21.5 \%)$ into a subinternship, $18(13.9 \%)$ into a second look program, and $48(36.7 \%)$ into other. Thirteen residents (10.0\%) did not answer this question. Figure is available in color online only. 
program attended a mean of 2.33 second looks (SD 1.08), while those who matched at their home, subinternship, or other programs attended an a mean of 0.74 (SD 0.81), 1.1 (SD 1.1), and 0.54 (SD 0.80) second looks, respectively. However, the inverse was not true; the number of second looks attended was not associated with type of program match $(p=0.2056)$. These findings indicate that respondents who matched to a second look program were likely to have attended more second looks, but attending more second looks did not necessarily mean a respondent would match at a second look program.

Several respondents commented on their experiences while interviewing as well as had suggestions for how to improve the entire process. Of the 8 respondents who commented on the survey, 5 suggested that programs in the same city or same region should coordinate their interviews to fall within the same week without overlap. Two respondents also noted that the opportunity to arrive early or stay an extra day to shadow chief residents allowed them to integrate a second look with their interview trip, giving them additional insight into the programs while reducing the amount of travel. Two respondents noted that they knew very early in the application process that they wished to stay at their home institution. As such, these respondents would have favored an avenue through which to communicate their preference and, therefore, reduce the associated costs of interviewing. Several suggestions ( $\mathrm{n}=$ 3 ) were made for large-scale changes to the very nature of the interview process. A common theme was the adoption of a centralized interviewing process, involving many applicants and programs in the same location. One potential addition to centralized interviewing would be the inclusion of a 2-part matching process, where applicants first participate in centralized interviews, create a rank list, and are then "matched" to a limited number of programs. Applicants could then visit these programs for additional interviews and tours, submit a second rank list, and then be matched to their final program.

\section{Discussion}

\section{Cost of Applying for Neurosurgery Residency Compared With Other Surgical Subspecialties and the Cost of Medical School}

We demonstrate that costs to applicants for neurosurgical residency are high. Our data show that medical students typically attend approximately 2 away rotations, 15 interviews, and 1 second look. The mean total expense for all components of the application process was $\$ 10,255$, (median \$10,000; IQR \$6500-\$13,000). Thus, the best estimate is that $\$ 3.44$ million were spent by the 335 applicants who sought neurosurgery positions in the 2014 NRMP.

After adjusting for inflation, the mean cost to applicants in the interview portion of the neurosurgery matching process $(\$ 7180)$ is higher than the average cost of interviewing to plastic surgery applicants $(\$ 4698)$ in 2009, reported by Rogers et al., and in 2013 (\$6262), reported by Clairborne et al. ${ }^{2,10}$ Kerfoot et al. reported that after adjusting for inflation the median cost of the interview process to applicants for urology residencies in 2006 was $\$ 4697.3$
The increased cost to our cohort is likely explained by the number of interviews attended; our cohort attended a mean of 15.3 interviews while the cohorts of Rogers et al. and Kerfoot et al. attended a mean of 7.0 and median of 12 interviews, respectively. ${ }^{3,10}$ Similarly, a higher proportion of our respondents attended more than 14 interviews compared with that of the cohort studied by Claiborne et al. (46\% vs $35 \%) .{ }^{2}$ We found that the cost of interviewing accounted for approximately $65 \%-70 \%$ of total expenses. The Association of American Medical Colleges reports that the average tuition and fees for the 2013-2014 academic year were $\$ 31,783$ for in-state students at public medical schools and $\$ 52,093$ for private medical schools. ${ }^{1}$ These figures do not include the cost of housing, transportation, health insurance, or other living expenses. The cost of the entire application process clearly represents a significant financial burden to applicants, in addition to their existing financial obligations.

\section{Predictors of Cost of Applying for a Neurosurgical Residency}

We were unable to detect any clear pattern associated with travel burden or cost of the application process in our analyses. Regardless of which region of the country medical students come from, they generally complete the same number of subinternships, attend the same number of interviews, and spend the same amount of money. Accordingly, contact with a program prior to the application process (matched to home or subinternship program) led to a statistically significant difference in number of interviews attended compared with no prior contact (13.5 vs 16.4 interviews attended, respectively), but there was no difference in interview or total expenses. The NRMP reports in "Charting Outcomes in the Match, 2014" that matched U.S. senior medical student applicants contiguously ranked an average of 14.9 programs compared with 9.5 for unmatched student. 7 This is likely a reflection of the number of interviews attended, and there may be differences in costs between the 2 groups that we were not able to capture in our survey. Stratifying respondents by medical school ranking revealed a significant difference between the 1st versus 4th quartiles for number of second looks attended but for no other measures. This pattern held true when comparing the top 10 schools versus all others. Potential explanations for the lack of differences across multiple types of stratifications include applicants applying broadly across the country, costs due to travel for interviews that cannot be grouped with other interviews, and savings from staying with friends or family while traveling. Our finding of a moderate correlation between the number of interviews attended and interview expenses is not surprising, and an intuitive solution to reducing costs for applicants is to reduce the number of interviews required to match.

\section{Proposals for Reducing the Financial Burden on Applicants}

Here we discuss suggestions from our respondents and a subcommittee of the SNS for reducing the costs of interviewing for a neurosurgery residency. The suggestions range from relatively minor modifications of the current 
system to wholesale changes in the way the interview process is conducted.

\section{Minor Changes to the Current Interview Process}

The current interview process does not take into account the pre-interview preferences of applicants and programs. Several of our respondents expressed frustration with this. Our data demonstrate that approximately $40 \%$ of medical students match to their home program or a program in which they did a subinternship. Although these students attended fewer interviews than applicants who went on to match at a program they did not have preinterview contact with, there was no statistical difference in the expenses associated with interviewing or with the entire application process. While we did not survey program directors for their input on the issue of pre-interview preferences, it is not difficult to imagine that there may be certain students from their home institution or subinternships who they know will be highly ranked prior to the interview process. One potential solution would be to allow students to "pre-match" to their home or subinternship program. Such an arrangement would likely require limits on the number of positions available for pre-match and close monitoring to ensure that students who do not pre-match have a fair opportunity to apply for programs. Clearly, solving the issue of pre-interview preference would require important changes to the application process, which would not be trivial to implement but may significantly reduce the financial burden of the application process for some applicants.

Approximately one-third of the residents voiced a preference for interviews to be held during subinternships. It is unclear to us how prevalent this practice is. However, the adoption of student interviews during subinternships would easily reduce the costs of interviewing without requiring significant modifications to the current system. Other relatively easy modifications proposed by a subcommittee of the SNS for reducing the financial burden on applicants include hard limits on the number of programs for which an applicant can interview and on the number of applicants a program can interview; standardization of the interview day structure to reduce lodging costs; and the creation of a centralized database of program characteristics including the number and subspecialty training of faculty, the number and types of cases carried out, hospital characteristics, and residency program structure with regard to rotations, calls, didactics, outcomes for graduates of the program, etc.

\section{Moderate Changes to the Current Interview Process}

The suggestion to coordinate interview dates according to city or region was very popular in our survey. Applicants wished to travel to 1 city or region and complete all of the relevant interviews without being required to return later in the interview season. Implementing such a system could be achieved at varying scales. One option is for programs in the same city or region to communicate directly with each other to coordinate interviews for 1 week each month, without overlap between programs. Alternatively, a larger scale effort could be organized so that programs in a particular geographic area would agree to complete their entire interview season in a set period of time, with coordinated dates to prevent overlap, or applicants and programs could be assigned to "rotations," where a given cohort of students may interview within each region in a given time frame before moving on to the next one.

\section{Major Changes to the Current Interview Process}

Several respondents expressed interest in a centralized, in-person interview process to significantly reduce travel requirements. One paradigm would be to hold centralized interviews only in large hub cities with key faculty and residents. This system would significantly save time and money for applicants; however, it would deprive them of the opportunity to see the city in which the program is situated, tour the facilities, and meet the residents and faculty who did not travel for the interviews. A combined approach would use the centralized regional interviews as only a screening mechanism to determine which applicants will receive an interview at the program. In such a system, the number of interviews for each applicant and the number of applicant invitations for each program would be limited to prevent hoarding of interviews by exceptional candidates. Applicants would then interview at a limited number of programs with some degree of assurance that they would match.

\section{Strengths and Limitations}

Our study has several strengths and limitations. One key strength is that we conducted the survey in partnership with the SNS and confirmed that responses only came from 1st-year neurosurgery residents who had gone through the match process and succeeded. Previous studies addressing the question of how to reduce interview costs used anonymous web-based surveys, which can be problematic because anyone can answer, thus skewing the results. ${ }^{4}$ Our survey also benefited from a response rate of $64.4 \%$, which is robust considering a previous study surveying 1st-year neurosurgery residents in 2013 yielded a 20\% response rate. ${ }^{5}$ Studies examining email- or Internet-based surveys have shown that, generally, such survey response rates range from $20 \%$ to $47 \%$. 911 The key limitation of our results lies in the fact that we did not capture information from students who failed to match, a population that can variably comprise U.S. medical students, graduated U.S. medical students, students from Caribbean medical schools, and international medical graduates. We also did not capture detailed information pertaining to travel factors such as mode of transportation, number of flights, free lodging with friends and family, and revisits to cities for interviews at different programs. Our results likely cannot be extrapolated to the application process for neurosurgical training programs outside of the United States given the comparatively large size of the country and relatively large number of training programs. Similarly, our results only reflect a single cohort of matched residents from 2014 and may not be representative of other years.

\section{Conclusions}

The process of applying for a neurosurgical residency position is a costly one for applicants. We demonstrate that 
regardless of a student's pre-interview preferences or medical school location, the cost of applying for a position in neurosurgery is uniformly high. All of the potential suggestions presented in this paper for reducing the financial burden on applicants would require changes on the part of applicants and residency programs. Unexpected consequences could make such changes seemingly difficult. However, a commitment to a more efficient and rational system for interviewing applicants would significantly benefit both applicants and programs.

\section{References}

1. Association of American Medical Colleges: Aspiring Docs. (https://students-residents.aamc.org/choosing-medical-career/ medical-careers/aspiring-docs/) [Accessed January 12, 2016]

2. Claiborne JR, Crantford JC, Swett KR, David LR: The plastic surgery match: predicting success and improving the process. Ann Plast Surg 70:698-703, 2013

3. Kerfoot BP, Asher KP, McCullough DL: Financial and educational costs of the residency interview process for urology applicants. Urology 71:990-994, 2008

4. Lieber BA, Wilson TA, Bell RS, Ashley WW Jr, Barrow DL, Wolfe SQ: Gauging the feasibility of cost-sharing and medical student interest groups to reduce interview costs. Neurosurg Focus 37(5):E11, 2014

5. Marasa LH, Pittman TA: Factors neurosurgery candidates use when choosing a residency program. J Neurosurg 120:167-172, 2014

6. National Resident Matching Program: Charting Outcomes in the Match, 2009. (http://www.nrmp.org/wp-content/uploads/2013/08/chartingoutcomes2009v3.pdf) [Accessed January 8,2016$]$

7. National Resident Matching Program: Charting Outcomes in the Match, 2014. (http://www.nrmp.org/wp-content/ uploads/2014/09/Charting-Outcomes-2014-Final.pdf) [Accessed January 8, 2016]

8. National Resident Matching Program: Results and Data: 2014 Main Residency Match. (http://www.nrmp.org/ wp-content/uploads/2014/04/Main-Match-Results-andData-2014.pdf) [Accessed January 8, 2016]

9. Nulty DD: The adequacy of response rates to online and paper surveys: what can be done? Assess Eval High Educ 33:301-314, 2008

10. Rogers CR, Gutowski KA, Munoz-Del Rio A, Larson DL, Edwards M, Hansen JE, et al: Integrated plastic surgery residency applicant survey: characteristics of successful applicants and feedback about the interview process. Plast Reconstr Surg 123:1607-1617, 2009

11. Schonlau M, Fricker RD, Elliott MN: Conducting Research Surveys via E-Mail and the Web. Santa Monica, CA: Rand Corporation, 2002

12. U.S. News \& World Report: Best medical schools: research. (http://grad-schools.usnews.rankingsandreviews. com/best-graduate-schools/top-medical-schools/researchrankings?int=98fd08) [Accessed January 12, 2016]

\section{Disclosures}

The authors report no conflict of interest concerning the materials or methods used in this study or the findings specified in this paper.

\section{Author Contributions}

Conception and design: Friedlander, Agarwal, Okonkwo, Barrow. Acquisition of data: all authors. Analysis and interpretation of data: all authors. Drafting the article: all authors. Critically revising the article: all authors. Reviewed submitted version of manuscript: all authors. Statistical analysis: Choi. Administrative/ technical/material support: Friedlander. Study supervision: Friedlander.

\section{Supplemental Information Online-Only Content}

Supplemental material is available with the online version of the article.

Supplemental Figures and Tables. http://thejns.org/doi/suppl/ 10.3171/2015.12.JNS15488.

\section{Correspondence}

Robert M. Friedlander, Department of Neurological Surgery, University of Pittsburgh Medical Center, 200 Lothrop St., Ste. B-400, Pittsburgh, PA 15213-2582. email: friedlanderr@upmc.edu. 